\title{
Endless forms most beautiful
}

\author{
Jerry A. Coyne
}

Genetics, Speciation and the Founder Princlple. Edited by L. V. Giddings, K. Y. Keneshiro and W. W. Anderson. Oxford University Press: 1989. Pp.373. £54, \$65.

Although Darwin's finches hold pride of place as examples of rampant island speciation, they are far overshadowed by the Drosophila of Hawaii. Only one tenthousandth of the Earth's land surface, the Hawaiian islands harbour more than a quarter of its 2,000 species of Drosophila. The systematics and genetics of this group, moreover, are far better understood than those of any other island radiation.

The Hawaiian Drosophila story is due largely to one tireless man, Hampton Carson. After a distinguished career in the mainland United States, Carson moved to Hawaii and soon realized the value of the native flies for studying speciation. Following the taxonomic groundwork of Elmo Hardy, Carson assumed leadership of the Hawaiian Drosophila project, which produced massive amounts of ecological, genetic and systematic data. This impressive body of work is commemorated in Carson's Festschrift, Genetics, Speciation and the Founder Principle, devoted mainly to Drosophila but also describing work on plants, mole rats and the Yanomama Indians. The research ranges from old-fashioned natural history to DNA sequencing, its variety a tribute to Carson's broad approach to speciation.

The book is, however, more than just a Festschrift: it is a manifesto for the Hawaiian group's theory of speciation, the 'founder effect'. The older explanation for riotous speciation on islands and archipelagoes is that suggested by Darwin and elaborated by his successors: these areas provide a unique combination of empty habitats, novel environments and geographical isolation. Rare invading groups evolve quickly, producing species as a by-product. As suggested by its name, 'adaptive radiation', this process is driven largely by natural selection, although sexual selection must often be important.

The founder effect theory, on the other hand, assigns a major role in speciation to genetic drift. According to this scheme, small colonizing populations experience random changes in allele frequency. This drift makes them temporarily maladapted, traversing valleys of low fitness until natural selection hauls them up a new adaptive peak. The process is similar to Sewall Wright's famous 'shifting-balance' theory of evolution, with the adaptive valleys representing reproductive isolation between species. Since first suggested by Ernest Mayr, the concept of the founder effect has undergone many changes, which Will Provine clarifies in a fine essay. It is important, however, to distinguish this theory from that of founder events, the idea that speciation may occur after a few individuals invade a new area. Unlike founder effects, founder events are not disputed.

Understanding speciation on islands is a major task of evolutionary biology. Although this volume contains much fascinating information (particularly the work on Hawaiian plants by Ganders and Carr et al.), it does little to resolve the issue, because most authors do not weigh the founder-effect theory against its alternative. Instead, chapter after chapter describes intriguing work, but then argues post facto that the results are consistent with founder effects. Unfortunately, virtually every observation is also consistent with adaptive radiation. Epistasis between genes causing speciation, for example, is repeatedly cited as evidence for founder effects. Yet as Dobzhansky and Muller pointed out half a century ago, the neodarwinian model predicts similar results (genes causing hybrid sterility and inviability must do so by interacting with other genes). Rapid speciation after founder events, another favourite argument for founder effects, is just as consistent with the notion that strong natural selection follows infrequent colonization.

I am not sure why these authors reject the traditional view, and it is difficult to imagine what evidence would critically support their hypothesis. It is hard enough to demonstrate that a species was once small enough to experience strong genetic drift (and we have no such evidence in the Hawaiian Drosophila, which show much molecular polymorphism), but it is nearly impossible to show that this drift was an important cause of reproductive isolation. For exactly the same reasons, Wright's shifting-balance theory remains, after 60 years, a magnificent but largely untestable view of evolution in nature. There are, to be sure, a few laboratory experiments showing that repeated bouts of genetic drift can cause some reproductive isolation (two are described in this volume), but their design makes them rather unrealistic models of island speciation.

To be fair, it is nearly as difficult to find firm evidence for the process of adaptive radiation. Can we then draw any conclusion about how speciation works on islands? I think there are several reasons for favouring the traditional explanation. First, the theory of founder effects is not a model, but a set of verbal assertions. More rigorous mathematical models by Barton, Rouhani, and Charlesworth (barely mentioned here) show that founder events very rarely produce founder effects. It therefore seems unlikely that more than a small fraction of island species can arise by that process. Second, the theory of founder effects invokes many more assumptions than that of adaptive radiation. The former requires complicated mixtures of special genetic architectures, repeated population bottlenecks, and strong epistasis, whereas the latter requires only that selected genes pleiotropically cause reproductive isolation (this is inevitable under sexual selection). Adaptive radiation is therefore likely to occur under a much wider range of conditions in nature. Third, there is no evidence that the genome must be disorganized by genetic drift before a new species can arise. Artificial selection on plants and animals readily produces aspects of reproductive isolation such as mating discrimination. Fourth, there are many cases of continental radiations in which speciation apparently followed the sundering of continuous habitat. These examples, which include Death Valley pupfish, Australian eucalyptus and neotropical butterflies, show that prolific speciation does not require founder events. Fifth, both continental and island species show recurring patterns of speciation: the preferential sterility and inviability of heterogametic hybrids (Haldane's rule), and its causation by genes on the $\mathrm{X}$ chromosome. These common patterns imply a common process in all species, not a unique evolutionary path for those on islands. Finally, there is evidence from Darwin's finches and the monkey flower Mimulus that reproductive isolation can result directly from adaptation in nature. We have no similar evidence for founder effects.

As a historical phenomenon, speciation is slow to yield its secrets. But its study is made even more difficult by a tendency to harmonize every observation with some favoured theory while ignoring the alternatives. The advocates of founder effects must tell us what observations can prove their theory wrong. Only then can we test it against its competitors and continue to build the remarkable edifice begun by Carson.

Jerry A. Coyne is in the Department of Ecology and Evolution, University of Chicago, Chicago, IIIinois 60637, USA.

\section{New In paperback}

- What Do You Care What Other People Think? by R. P. Feynman is his second and final volume of memoirs (see review Nature 336, 432; 1988). Published by Unwin Hyman, price $£ 4.50$.

- Great Geological Controversies 2 nd edn by A. Hallam is available from Oxford University Press, price $£ 12.50$. For review see Nature 306, $128 ; 1983$. 